\title{
Exogenous abscisic acid alleviates the toxicity of nickel in wheat seedlings
}

\author{
Xue $\mathrm{LI}^{1,3}$, Ming $\mathrm{ZHANG}^{1,3}$, and Tian-peng $\mathrm{GAO}^{1,2,3 *}$ \\ ${ }^{1}$ School of Geography and Environmental Engineering, Lanzhou City University, Lanzhou 730070, China \\ ${ }^{2}$ School of Biological and Environmental Engineering, Xi'an University, Xi'an 710065, China \\ ${ }^{3}$ Engineering Center for Pollution Control and Ecological Restoration in Mining of Gansu Province, Lanzhou, 730070, China
}

\begin{abstract}
In order to evaluate the effects of exogenous abscisic acid (ABA) in alleviating nickel (Ni) stress in wheat plants. We studied the changes of biochemical and physiological in wheat seedlings exposed to 250 $\mu \mathrm{M} N i$ with or without different treatments of ABA. Exposed to Ni $(250 \mu \mathrm{M})$ caused adverse effect on growth of wheat seedlings, which was accompanied by increased the concentrations of superoxide anion $\left(\mathrm{O}_{2}^{-}\right)$and malondialdehyde (MDA). However, exogenous application of ABA $(2.5$ and $5 \mu \mathrm{M})$ alleviated the Ni-induced inhibition of plant growth, decreased the concentrations of $\mathrm{O}_{2}{ }^{-}$and MDA in wheat shoots. Further, application of ABA significantly modulated the activities of antioxidant enzymes and enhanced content of proline and soluble sugar in Ni-stressed wheats, but the application of $20 \mu \mathrm{M}$ of ABA had no different significantly response for these parameters. The results indicated that application of ABA enhanced the antioxidant defense activities in Ni-stressed wheats, thus alleviating Ni-induced oxidative injury and enhancing Ni tolerance.
\end{abstract}

\section{Introduction}

Nickel is a essential plant minerals which is required by plants in order to maintain healthy growth and development but it become extremely toxic in higher concentrations. The accumulation of $\mathrm{Ni}$ in plants can cause numerous morphological and physiological changes. At the morphological level, a high concentrations of $\mathrm{Ni}$ causes plant growth retardation, chlorosis and wilting [1]. At the physiological level, excess $\mathrm{Ni}$ results in an inhibition of chlorophyll synthesis [2], damage to photosynthetic electron transport chain [3], induction of oxidative stress [4], and changes in enzyme activity [5]. Likewise, $\mathrm{Ni}$ promotes the accumulation of reactive oxygen species (ROS) causing lipid peroxidation and metabolism imbalance. Plants possess antioxidant systems to scavenge reactive ROS by increasing the activities of key enzymatic and non-enzymatic antioxidants, including superoxide dismutase (SOD), peroxidase (POD) and ascorbic acid [6].

Phytohormones play important roles in the coordination of adaptive responses to environmental stresses. Abscisic acid (ABA) is classified as a sesquiterpene hormone for regulating many plants physiological responses to various abiotic stresses. The level of ABA in plant tissues has been shown to increase upon exposure to environmental stresses such as drought, salt and copper stress $[7,8]$. It is reported that exogenous application of ABA influences a range of diverse processes in plants, such as seed germinations, growth and development, photosynthesis, secondary metabolism and gene expression $[9,10]$. There is also evidence that ABA can ameliorate the damaging effects of chilling and heavy metals $[11,12]$. However, to the best of our knowledge, whether exogenous applications of ABA can alleviate Niinduced oxidative stress in wheat seedlings, has not been reported yet. Therefore, the aim of this study was to examine whether ABA could alleviate the injurious effects of Ni stress and regulate wheat plant growth by regulating the antioxidant enzymes activities and osmolytes involved in stress tolerance.

\section{Materials and methods}

\subsection{Plant growth and treatment}

Wheat (Triticum aestivum L.) seeds were surfacesterilized with $1 \%(\mathrm{w} / \mathrm{v}) \mathrm{NaClO}$ for $10 \mathrm{~min}$ and rinsed thoroughly several times with sterile distilled water, then the seeds were soaked in distilled water for $8 \mathrm{~h}$, the seeds were placed into petri dishes containing three layers gauze moistened with distilled water and germinated for $3 \mathrm{~d}$ at $25{ }^{\circ} \mathrm{C}$ under dark conditions. When the plumule emerged, seedlings were cultivated in a climate-controlled room under the following conditions: $25^{\circ} \mathrm{C}, 12 / 12 \mathrm{~h} \mathrm{light/dark}$ photoperiod and $65 \pm 5 \%$ relative humidity. The seedlings were treated with 0 (control), 50, 100, 250, $500 \mu \mathrm{M} \mathrm{NiSO}_{4}$ and renews every $2 \mathrm{~d}$. After $4 \mathrm{~d}$, the shoot and root length were measured, and the relevant biomarkers were measured.

* Corresponding author: zkgtp@163.com (T.G.)

ORCID: 0000-0001-6821-3836 
We found that the growth of wheat was clearly inhibited when the concentration of $\mathrm{NiSO}_{4}$ was $250 \mu \mathrm{M}$. This dose of $\mathrm{NiSO}_{4}$ was selected for the next phase of the experiment with ABA. The $3 \mathrm{~d}$ old seedlings of wheat were pretreated with the $\operatorname{ABA}(0,2.5,5,10,20 \mu \mathrm{M})$ for 8 h before exposure to $250 \mu \mathrm{M} \mathrm{NiSO}$, respectively. The control wheat seedlings were only treated with distilled water. The growth conditions of the wheat seedlings were as described earlier. The treated seedlings were harvested for analysis after $4 \mathrm{~d}$.

\subsection{Lipid peroxidation and superoxide anion $\left(\mathrm{O}_{2}^{-}\right)$}

Malondialdehyde (MDA) content was assayed by the method of Thomas et al. [13]. $\mathrm{O}_{2}^{-}$was determined as described by Jiang and Zhang [14].

\subsection{Proline and soluble sugars}

Proline content was measured according to the method of Bates et al. [15]. The contents of soluble sugars was measured with the method described by Chow and Landhausser [16].

\subsection{Antioxidant enzyme activities}

Fresh samples $(0.2 \mathrm{~g})$ were grinded to homogenize in 5.0 $\mathrm{mL}$ of $50 \mathrm{mM}$ potassium phosphate buffer $(\mathrm{pH} 7.8)$ by an ice-cold mortar and pestle to extract shoot enzymes. The homogenates were centrifuged at $10,000 \times \mathrm{g}$ for $15 \mathrm{~min}$ at $4{ }^{\circ} \mathrm{C}$, and the supernatants were used for analysing the activity of SOD (EC 1.15.1.1.) [17], POD (EC 1.11.1.7.) [17] and catalase (CAT) (EC 1.11.1.6.) [18].

\subsection{Statistical analysis}

Statistical analysis was performed using SPSS Version 19.0 software. Data are presented as mean \pm standard deviation (SD). Duncan's multiple test were applied to determine the significant difference $(p<0.05)$ among the treatments.

\section{Results}

As shown in Table 1, compared to the control, there was no significant effects in root and shoot lengths of wheat in
50 and $100 \mu \mathrm{M}$ Ni treatments. However, the presence of 250 and $500 \mu \mathrm{M}$ Ni significantly reduced the lengths of root and shoot in wheat seedlings. The lengths of root and shoot decreased by 31.39 and $22.56 \%$ in $250 \mu \mathrm{M} \mathrm{Ni}$ treatments, respectively, relative to the control. The accumulation of MDA was dose dependent in roots treated with 50-500 $\mu \mathrm{M} \mathrm{Ni}$. Meanwhile, we also observed a similar increasing trend in $\mathrm{O}_{2}{ }^{-}$contents of roots. However, MDA and $\mathrm{O}_{2}^{-}$contents in shoots were no significant effects under $100 \mu \mathrm{M}$ Ni treatment as compared with the control. In accordance with these results, $250 \mu \mathrm{M}$ Ni was used as the treatment concentration.

As shown in Table 2, exposure of wheat seedlings to $250 \mu \mathrm{M}$ Ni significantly decreased root and shoot lengths. However, exogenous application of ABA produced significant changes in plants growth, and only 2.5 and $5 \mu \mathrm{M}$ ABA significantly enhanced root and shoot lengths of wheat seedlings. This effect was even more pronounced for the group with $5 \mu \mathrm{M} \mathrm{ABA}$; it improved the root and shoot lengths of plants by 27.66 and $19.28 \%$, respectively, as compared to $\mathrm{Ni}$ alone treatment. The results indicated that the alleviative effect by exogenous application of ABA on Ni-induced growth inhibition was more obvious in roots than in shoots. Whereas application with $20 \mu \mathrm{M}$ ABA reduced significantly shoot growth as compared to Ni alone treatment.

Wheat seedlings were treated with $250 \mu \mathrm{M}$ Ni for $4 \mathrm{~d}$, the proline level in the shoots increased to $25.85 \%$ of that of the untreated control (Table 2). ABA improved further the level of proline in the shoot of plants in comparison to the control. In contrast, $5 \mu \mathrm{M}$ ABA had the greatest effect on proline level, which increased by $16.04 \%$ in shoot tissues than that of $\mathrm{Ni}$ alone treatment. In addition, the contents of soluble sugar was significantly decreased by $\mathrm{Ni}$ treatment as compared to the control. After application of different concentrations ABA, the contents of soluble sugar in shoots were significantly increased by 26.06 , $62.29,18.81$ and $21.70 \%$, respectively, as compared to the treatment of Ni alone (Table 2).

The contents of MDA and $\mathrm{O}_{2}{ }^{-}$significantly increased in the shoots under Ni stress, about increased by $79.17 \%$ and $140.21 \%$ than that of control, respectively (Table 2). ABA reduced the accumulation of $\mathrm{MDA}$ and $\mathrm{O}_{2}^{-}$to varying extents in wheat seedlings. Especially, $\mathrm{ABA}$ at $5 \mu \mathrm{M}$ had the greatest effect, and MDA and $\mathrm{O}_{2}{ }^{-}$contents decreased by 20.83 and $32.92 \%$ in shoots, respectively, as compared to the treatment of $\mathrm{Ni}$ alone (Table 2).

Table1. Effects of $\mathrm{Ni}$ on growth and oxidative stress in wheat seedlings. Values show the means of four replicates $\pm \mathrm{SD}$. The different lower case represents statistically differences between treatments $(p<0.05)$.

\begin{tabular}{ccccccc}
\hline \multirow{2}{*}{$\begin{array}{c}\mathrm{Ni} \\
\mu \mathrm{M}\end{array}$} & \multicolumn{2}{c}{ Length $(\mathrm{cm})$} & \multicolumn{2}{c}{ MDA $\left(\mathrm{nmol} \mathrm{g}^{-1} \mathrm{FW}\right)$} & \multicolumn{2}{c}{$\mathrm{O}_{2}^{-}\left(\mathrm{nmol} \mathrm{min}^{-1} \mathrm{~g}^{-1} \mathrm{FW}\right)$} \\
\cline { 2 - 7 } & Root & Shoot & Root & Shoot & Root & Shoot \\
\hline 0 & $7.84 \pm 0.50 \mathrm{a}$ & $8.32 \pm 0.47 \mathrm{a}$ & $5.19 \pm 0.96 \mathrm{~d}$ & $5.32 \pm 0.91 \mathrm{c}$ & $3.52 \pm 0.46 \mathrm{~d}$ & $3.19 \pm 0.61 \mathrm{c}$ \\
50 & $8.03 \pm 0.62 \mathrm{a}$ & $8.72 \pm 0.39 \mathrm{a}$ & $5.20 \pm 0.61 \mathrm{~d}$ & $4.98 \pm 0.72 \mathrm{c}$ & $3.47 \pm 0.49 \mathrm{~d}$ & $3.07 \pm 0.41 \mathrm{c}$ \\
100 & $7.22 \pm 0.39 \mathrm{a}$ & $8.11 \pm 0.37 \mathrm{a}$ & $6.98 \pm 0.44 \mathrm{c}$ & $5.98 \pm 0.77 \mathrm{c}$ & $4.74 \pm 0.46 \mathrm{c}$ & $4.31 \pm 0.66 \mathrm{c}$ \\
250 & $5.37 \pm 0.35 \mathrm{~b}$ & $6.44 \pm 0.46 \mathrm{~b}$ & $10.59 \pm 0.93 \mathrm{~b}$ & $9.81 \pm 0.42 \mathrm{~b}$ & $7.13 \pm 0.58 \mathrm{~b}$ & $7.61 \pm 0.59 \mathrm{~b}$ \\
500 & $3.03 \pm 0.52 \mathrm{c}$ & $3.17 \pm 0.35 \mathrm{c}$ & $14.60 \pm 0.43 \mathrm{a}$ & $31.18 \pm 0.91 \mathrm{a}$ & $9.50 \pm 0.61 \mathrm{a}$ & $10.42 \pm 1.04 \mathrm{a}$ \\
\hline
\end{tabular}


Table2. Effects of ABA on root and shoot lengths, proline, soluble sugar, malondialdehyde (MDA) and superoxide anion $\left(\mathrm{O}_{2}{ }^{-}\right)$of wheat seedlings under Ni stress. Values show the means of four replicates $\pm \mathrm{SD}$. Different lower case represents statistically significant differences between treatments $(p<0.05)$.

\begin{tabular}{ccccccc}
\hline $\begin{array}{c}\text { Treatments/ } \\
\text { Parameters }\end{array}$ & $\begin{array}{c}\text { Root length } \\
(\mathrm{cm})\end{array}$ & $\begin{array}{c}\text { Shoot length } \\
(\mathrm{cm})\end{array}$ & $\begin{array}{c}\text { Proline } \\
\left(\mu \mathrm{g} \mathrm{g}^{-1} \mathrm{FW}\right)\end{array}$ & $\begin{array}{c}\text { Soluble sugar } \\
\left(\mathrm{mg} \mathrm{g}^{-1} \mathrm{FW}\right)\end{array}$ & $\begin{array}{c}\text { MDA(nmol g-1 } \\
\mathrm{FW})\end{array}$ & $\begin{array}{c}\mathrm{O}_{2}^{-}\left(\mathrm{nmol}^{-1}\right. \\
\left.\mathrm{min}^{-1} \mathrm{~g}^{-1} \mathrm{FW}\right)\end{array}$ \\
\hline Control & $8.16 \pm 0.54 \mathrm{a}$ & $8.99 \pm 0.54 \mathrm{a}$ & $17.76 \pm 1.10 \mathrm{e}$ & $21.69 \pm 1.04 \mathrm{~b}$ & $5.57 \pm 0.99 \mathrm{c}$ & $3.25 \pm 0.42 \mathrm{e}$ \\
$\mathrm{Ni}(250 \mu \mathrm{M})$ & $5.48 \pm 0.42 \mathrm{c}$ & $6.49 \pm 0.43 \mathrm{c}$ & $22.35 \pm 0.54 \mathrm{~cd}$ & $15.25 \pm 1.25 \mathrm{~d}$ & $9.98 \pm 0.55 \mathrm{a}$ & $7.81 \pm 0.33 \mathrm{a}$ \\
$\mathrm{Ni}+$ ABA $(2.5)$ & $6.40 \pm 0.49 \mathrm{~b}$ & $7.25 \pm 0.19 \mathrm{~b}$ & $24.55 \pm 0.66 \mathrm{ab}$ & $19.22 \pm 1.19 \mathrm{c}$ & $7.96 \pm 0.26 \mathrm{~b}$ & $5.45 \pm 0.31 \mathrm{~d}$ \\
$\mathrm{Ni}+$ ABA (5) & $6.99 \pm 0.61 \mathrm{~b}$ & $7.75 \pm 0.33 \mathrm{~b}$ & $25.93 \pm 1.06 \mathrm{a}$ & $24.74 \pm 1.22 \mathrm{a}$ & $7.89 \pm 0.89 \mathrm{~b}$ & $5.24 \pm 0.37 \mathrm{~d}$ \\
$\mathrm{Ni}+$ ABA $(10)$ & $5.38 \pm 0.32 \mathrm{c}$ & $6.33 \pm 0.54 \mathrm{c}$ & $23.19 \pm 0.37 \mathrm{bc}$ & $18.12 \pm 1.29 \mathrm{c}$ & $9.59 \pm 0.73 \mathrm{a}$ & $6.13 \pm 0.16 \mathrm{c}$ \\
$\mathrm{Ni}+$ ABA $(20)$ & $5.18 \pm 0.27 \mathrm{c}$ & $5.29 \pm 0.23 \mathrm{~d}$ & $21.16 \pm 0.71 \mathrm{~d}$ & $18.55 \pm 0.77 \mathrm{c}$ & $10.30 \pm 0.93 \mathrm{a}$ & $7.45 \pm 0.29 \mathrm{a}$ \\
\hline
\end{tabular}
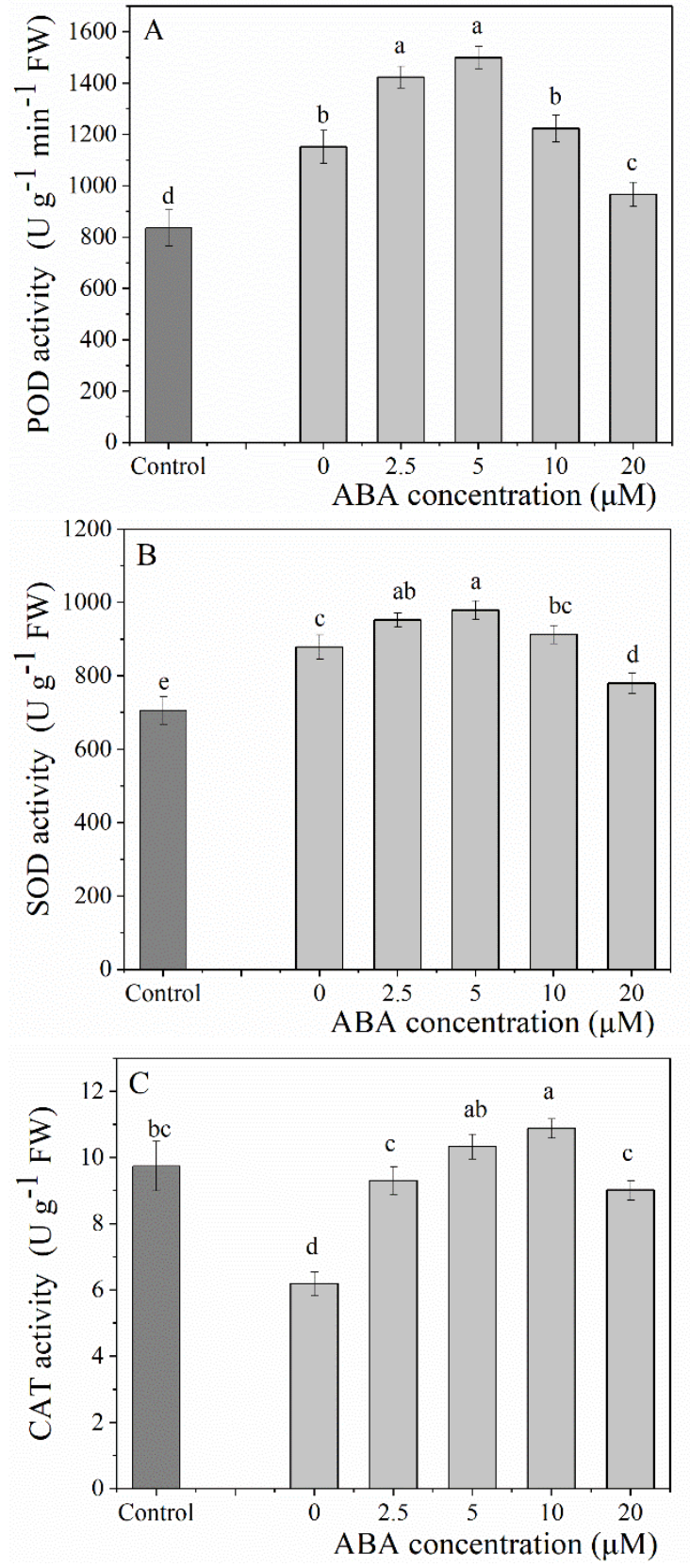

Figure 1. Effects of ABA on POD (A), SOD (B), CAT (C) in shoots of wheat seedlings under Ni stress. Bars $(\mathrm{n}=4)$ showing the different letters are significantly different at $p<0.05$ as determined by Duncan analyze.
The activities of SOD and POD were found to be increased under Ni toxicity. In contrast, the application of ABA $(2.5$ and $5 \mu \mathrm{M})$ enhanced further in the activities of these enzymes under $\mathrm{Ni}$ stress in comparison to the treatment of Ni alone. (Fig. 1A-B). Nevertheless, the CAT activity was decreased in Ni-stressed wheats, but the application of ABA $(2.5-20 \mu \mathrm{M})$ overcame the adverse effects of $\mathrm{Ni}$-stress, causing a notable increase in the activity of CAT of shoots tissues (Fig. 1C).

\section{Discussion}

In the present study, the symptoms of Ni toxicity on wheat plants are growth inhibition at the very early stage of their development. Shoot and root growth in wheat plants were decreased significantly when $\mathrm{Ni}$ concentrations reached $250 \mu \mathrm{M}$ (Table 1). However, we found that exogenous ABA was able to ameliorate the toxic effect of $\mathrm{Ni}$ on the growth of wheat seedlings. Inhibition of growth in wheat seedlings might result from Ni-caused alterations of metabolic and biochemical processes [19]. The contents of MDA and $\mathrm{O}_{2}^{-}$significantly increased at 250 and $500 \mu \mathrm{M}$ $\mathrm{Ni}$ in both shoots and roots of plants (Table 1). These results showed that the oxidative stress and the peroxidation of membrane lipids were caused by Ni stress. Previous studies have demonstrated that MDA content can be induced in wheat contaminated with heavy metal such as $\mathrm{Ni}, \mathrm{Cu}$ and $\mathrm{Cd}[20,21]$.

Previous studies have demonstrated that ABA has great potential to enhance the tolerance to certain stresses including drought, saline-alkaline in different plants [22, 23]. Generally, low concentrations of ABA can improve plant resistance to adverse environments, and high concentrations of ABA can cause high levels of oxidative stress, leading to a decreased resistance to environmental stress [14, 24]. In this study, exogenous application of low concentrations of ABA $(2.5$ and $5 \mu \mathrm{M})$ significantly alleviated the deleterious effects of $\mathrm{Ni}$ on plant growth (Table 2). Previously, it was stated that ABA application alleviated the copper induced growth retardation in Artemisia annua [25]. However, this mitigation effect gradually reduced with increasing concentrations of ABA, and $20 \mu \mathrm{M}$ ABA even inhibited even shoot growth.

In comparison to control plants, the content of proline was improved under Ni stress both by ABA treatment and treatment free plants (Table 2). The proline accumulation is essential to maintain osmotic adjustment under Ni stress. 
It has been proposed that proline plays an important role in the antioxidative properties of heavy metal-stressed [26]. Additionally, Ni-stressed plants exhibited a significant reduction in soluble surgar. Exogenous application of ABA led to the increase in soluble surgar in shoots of plants (Table 2). Soluble surgar are known to contribute to the osmotic adjustment [24], thus high level of soluble surgar is beneficial for enhanced tolerance of the plants under Ni stress. This suggested that ABA treatment could elevate proline and soluble surgar to withstand $\mathrm{Ni}$-induced injury.

Our results showed that the growth of wheat plants were decreased significantly under Ni $(250 \mu \mathrm{M})$ stress, accompanying with the significant increase the contents of $\mathrm{O}_{2}{ }^{-}$and MDA (Table 2). Exogenous application of ABA reversed this adverse effect of $\mathrm{Ni}$, causing a significant decrease in the $\mathrm{O}_{2}^{-}$and MDA contents. Moreover, Ni toxicity in plants may be attributed to increasing lipid peroxidation leading to oxidative damage [27]. To prevent the Ni-induced oxidative damage on plants, plants have antioxidant defense mechanisms. In the present study, the activity of POD was increased in response to only Nistressed treatment and continually increase was observed by low concentrations of ABA treatment plus Ni. (Fig.1A). Similar trend was found for SOD (Fig. 1B). SOD catalyzes the conversion of $\mathrm{O}_{2}{ }^{-}$to $\mathrm{O}_{2}$ and $\mathrm{H}_{2} \mathrm{O}_{2}$ [28]. Notably, results showed the content of $\mathrm{O}_{2}^{-}$was at ABA treatment plus $\mathrm{Ni}$ lower than that of $\mathrm{Ni}$ alone, thus $\mathrm{ABA}$ enhanced the antioxidative system to scavenge the accumulation of $\mathrm{O}_{2}^{-}$. In addition, $\mathrm{Ni}$ stress caused marked decrease in the activity of CAT, whereas ABA treatment induced a significant increase in the activity of CAT in shoots of plants (Fig. 1C) This is supported by the study of Jiang et al [29], who observed that ABA pretreatment enhanced the actions of SOD, CAT and ascorbate peroxidase enzymes in Zea mays seedling under abiotic stress. In fact, the results indicate that the increase in the activities of the antioxidant enzymes were not sufficient to protect cell membrane against $\mathrm{Ni}$ toxicity. However, this oxidative damage was alleviated by ABA treatment (Table 2). The application of ABA elevated enzymatic antioxidants in shoots of wheats, hence leading to alleviation of the oxidative damage as indicated by the lowered $\mathrm{O}_{2}{ }^{-}$and MDA levels.

\section{Conclusion}

In summary, $\mathrm{ABA}$ may attenuate $\mathrm{Ni}$ toxicity in wheat seedling exposed to Ni stress, which probably includes the regulation of the antioxidant system and the improvement of osmotic adjustment. This suggests that an appropriate concentrations ABA could be used as a potential growth regulator to alleviate $\mathrm{Ni}$ induced toxicity in plants.

\section{Acknowledgements}

This work was financially supported by the National Natural Science Foundation of China (NSFC 31860176), Key Research and Development Program of Gansu Province (20YF3FA037), Key Research and Development
Program of Shanxi Province (2020ZDLSF06 06) and XAWLKYTD012. We are grateful to all anonymous reviewers whose comments improved the quality of the manuscript.

\section{References}

1. N. Pandey, C.P. Sharma, Plant Sci. 163, 753-758, (2002)

2. E.Gajewska, M. Sklodowska, M. Slaba, J. Mazur, Biol. Plant. 50, 653-659, (2006)

3. N. Mohanty, I. Vass, S. Demeter, Physiol. Plant. 76, 386-390, (1989)

4. S. Baccouch, A. Chaoui, E. El Ferjani, J. Plant Nutr. 24, 1085-1097, (2001)

5. R. Boominathan, P. M. Doran, New Phytol. 156, 205215, (2002)

6. R. Mittler, S. Vanderauwera, M. Gollery, F. Van Breusegem, Trends. Plant Sci. 9, 490-498, (2004)

7. J. H. Zhang, W. S Jia, J. C. Yang, A. M. Ismail, Field Crops Res, 97, 111-119, (2006)

8. F. K. Zengin, S. Kirbag, J. Environ. Biol. 28, 561, (2007)

9. M. H. Ibrahim, H. Z. Jaafar, Molecules, 18, 79577976, (2013)

10. S. K. Sah, K. R. Reddy, J. Li, Front. Plant Sci. 7, 126, (2016)

11. G. J. Wang, W. Miao, J. Y. Wang, D. R. Ma, J. Q. Li, W. F. Chen, J. Agron. Crop Sci, 199, 200-208, (2013)

12. G. M. Shen, J. K. Niu, Z. X. Deng, Plant Physiol. Biochem, 118, 471-478, (2017)

13. J. C. Thomas, M. Perron, E.C Davies, Plant Sci. 167, 259-266, (2004)

14. M. Y. Jiang, J. H. Zhang, Plant Cell Physiol. 42, 1265-1273, (2001)

15. L. S. Bates, R. P. Waldren, I. D. Teare, Plant Soil, 39, 205-207, (1973)

16. P. S. Chow, S. M. Landhausser, Tree Physiol, 24, 1129-1136, (2004)

17. C. S. Gu, Y. H. Yang, Y. F. Shao, K. W. Wu, Z. L. Liu, S Afr J. Bot, 114, 267-271, (2018)

18. H. B. Shao, Z. S. Liang, M. A. Shao, Colloid. Surface B. 45, 7-13, (2005)

19. K. U. Parlak, NJAS - Wagen J. Life Sc, 76, 1-5, (2016)

20. E. Gajewska, M. Sklodowska, Ecotox. Environ. Saf, 73, 996-1003, (2010)

21. R. Z. Lin, X. R. Wang, Y. Luo, W. C. Du, H. Y. Guo, D.Q. Yin, Chemosphere, 69, 89-98, (2007)

22. L. L. Yang, L. Yang, Y. M. Lan, Y. Zhao, M. Han, L. M. Yang, Ind Crop. Prod, 154, 112686, (2020)

23. L. X. Wei, B. S. Lv, M. M. Wang, H. Y. Ma, H. Y. Yang, X. L. Liu, C. J. Jiang, Z. W. Liang, Plant Physiol. Biochem, 90, 50-57, (2015)

24. J. Wang, J. Chen, K. Pan, Environ Sci Pollut Res, 20, 1441-1449, (2013) 
25. A. Zehra, S. Choudhary, K. I. Wani, M. Naeem, M. M. A. Khan, T. Aftab, Plant Physiol. Biochem, 156, 125-134, (2020)

26. J. Matysik, Alia. Bhalu, B.P. Mohanty, Curr. Sci. 82, 525-532, (2002)

27. S. Baccouch, A. Chaoui, E. El Ferjani, Plant Physiol. Biochem. 36, 689-694, (1998)

28. C. H. Foyer, G. Noctor, Physiol. Plant, 119, 355-364, (2003)

29. M. Y. Jiang, J. H. Zhang, Free Radic. Res. 36, 10011015, (2002) 